\title{
The ethics of knowledge production - Pacific challenges
}

\author{
Rosemary Du Plessis and Peggy Fairbairn-Dunlop
}

\section{Introduction}

People from all over the Pacific $^{1}$ came to talk about ethical principles relating to the preservation, production, exchange and use of knowledge at the Regional Pacific Ethics of Knowledge Production Workshop in Apia (1315 November 2007). This workshop was the third in a series of UNESCO meetings between 2005 and 2007 that encouraged Pacific-wide debate on the Universal Declaration on Bioethics and Human Rights (UDBHR) (UNESCO 2005) ${ }^{2}$ and discussion of ethics-related issues more generally. The articles in this Pacific section of the ISSJ on global knowledges are a sample of the positions debated and the insights generated at that workshop. They illustrate the connections and differences among Pacific peoples about issues relating to the ethics of science including fundamental questions about what counts as knowledge, how knowledge is produced and shared, and who benefits. They also demonstrate how Pacific people are taking responsibility for assessing the relevance of the UDBHR in the Pacific, articulating indigenous ethical principles,
Rosemary Du Plessis is an Associate Professor in Sociology at the University of Canterbury, Christchurch, New Zealand and a member of New Zealand National Commission for UNESCO. She was involved in organising both the Ethics of Knowledge Production Conference at Otago University in 2006 and the Regional Pacific Ethics of Knowledge Production Workshop at the Tofamamao Centre in Apia in 2007. She has a strong interest in the politics of knowledge and public engagement with the social, ethical and cultural issues associated with new technologies. With Richard Hindmarsh she has recently edited a special edition of New Genetics and Society 27 (3), which analyses trajectories in life sciences governance in Australasia. Born in the UK, she grew up in South Africa and has lived in New Zealand for most of her life.

Email: rosemary.duplessis@canterbury.ac.nz Peggy Fairbairn-Dunlop is Associate Professor and Inaugural Director of the Vaaomanu Pasifika (Pacific and Samoa Programme) at Victoria University, Wellington, New Zealand. Before taking up this post in 2006 Peggy was Social and Human Sciences Adviser at the Pacific UNESCO office (Apia) and coordinated Pacific regional teams to the first Asia-Pacific Bioethics Meeting (Bangkok 2005) and the Ethics of Knowledge Production Workshop at Otago University (February 2006). In New Zealand she continues working with the New Zealand National Commission for UNESCO on these issues and Toi te Taiao, the Bioethics Council, and was conference chair for the UNESCO Regional Pacific Ethics of Knowledge Production meeting in Apia (November 2007). She is Samoan.

Email: fairdun2@xtra.co.nz identifying the researchrelated questions they consider a priority and determining strategies for ethical research practice.

These UNESCO meetings have increased public discussion on ethics-related issues in the Pacific, made relevant research in this field available and widened the range of stakeholders who are now engaging in ethicsrelated discussions from many Pacific countries, including non-governmental organisations, policy analysts and researchers. However, of most significance has been the framing by Pacific people of Pacific ethical issues and the ways in which they might be addressed. Discussion has moved from a few small pockets of debate, largely in academic circles, to include conversations about the ethics of research in the natural and social sciences among people from a wide range of Pacific states, including a number of community groups. The outcome has been a more intensive sharing of knowledge as well as a better understanding of the ethical dilemmas generated by the increasing pace of technological development. 
Four Pacific participants attended the Asia-Pacific Ethics Forum in Bangkok (11-15 September 2005). They represented the Republic of the Marshall Islands, Fiji and Samoa and included tertiary educators, community researchers and policy-makers. At this forum, participants shared their own Pacific-grounded views with participants from Asia and noted some commonalities, especially in relation to spirituality. In addition, the Pacific team drew attention to potential tensions between what they described as the generic or universal approach of the UDBHR and Pacific ethics. They questioned how a universal declaration could reflect Pacific realities, aspirations and beliefs. They looked critically at the predominantly individual rights framework of the UDBHR and noted its incompatibility with Pacific ideals of collective rights. These and other questions informed the organisation of the Pacific section of the Ethics of Knowledge Production Conference that was organised by the New Zealand National Commission for UNESCO at Otago University, Dunedin (1214 February 2006).

The six delegates to this meeting from Pacific states comprised policy-makers, representatives of non-governmental organisations, academics and research practitioners. They included the UNESCO chair from the University of the South Pacific in Suva, the chair of the International Council for Pacific Research located at the National University of Samoa, a representative of the regional non-governmental organisation, the Pacific Islands Association of NGOs, and community agencies. New Zealandbased Pacific academics and community researchers also participated and, along with Māori researchers, shared their research journeys and ethical challenges. Organisations such as the New Zealand Health Research Council and Toi Te Taiao, the Bioethics Council, which until 2009 advised the government on the cultural, ethical and spiritual aspects of biotechnologies, participated in this event, alongside New Zealand representatives of the International Bioethics Committee and the World Commission on the Ethics of Scientific Knowledge and Technology.

Justice Michael Kirby, who had chaired the expert panel on the UDBHR, provided the keynote address at the Dunedin Conference, and both Māori and Pacific delegates raised questions about its focus on individual rights and the relative neglect of the rights of communities or collectivities. ${ }^{3}$ The issues raised were very similar to the concerns of Pacific delegates to the Bangkok Conference in 2005. Pacific delegates agreed that a standard-setting mechanism was needed to inform ethical research practice in the Pacific, but they considered that it needed to incorporate Pacific values, beliefs and practices. Conference participants resolved that a followup meeting should be held that would focus specifically on Pacific ethics. Funding for Pacific representation at this event was secured through the UNESCO Participation Programme by the New Zealand National Commission for UNESCO and the UNESCO office for the Pacific in Apia, and a pan-Pacific organising committee worked together to organise the Regional Pacific Ethics of Knowledge Production Workshop in November 2007. This meeting was opened by Dame Silvia Cartwright, former Governor-General of New Zealand and chair of the National Commission for UNESCO in New Zealand, who introduced the keynote speaker, Tui Atua Tupua Tamasese Ta'isi Efi, the Head of the Independent State of Samoa (MilaSchaaf, 2008).

\section{Pacific ethics: key themes}

A number of cross-cutting and inter-related themes emerged in these debates, which set the context for this collection of articles and the platform for continuing Pacific debate about the ethics of science, social science research protocols and bioethics. Ethics systems and processes were, and still are, central to every aspect of the life of Pacific indigenous communities. Although not documented, and long disregarded in the privileging of western ideas about ethical practice in the post-contact period, Pacific ethics processes integrate epistemological, pedagogical and methodological considerations. For Pacific people, as these articles illustrate, each daily life event is seen through a lens of ethical values, mores and codes of conduct that have developed over many years, while remaining responsive to changing times. The indigenous knowledge systems of the Pacific incorporate technical insights and detailed observations of natural, 
social and spiritual phenomena, which in turn are used to validate what is important in life what sustains people and what connects them to particular places and spaces, and is crucial to their identity. Spirituality, or the sacred, is fundamental - people are the carriers of the lifeblood of future generations and have complex responsibilities to their physical environment and other living things. In Pacific communities, knowledge is communally made, sanctioned, shared and used with the aim of achieving the good life for all members however this is defined.

Discussions about Pacific knowledge systems have highlighted a growing understanding that erosion of this knowledge is partly, but not only, due to the demise of community elders. Agreement about the urgent need to research and document this knowledge before more is lost has given rise to further questions about what knowledge should or could be passed on, to whom and how this should be done. In traditional times knowledge was passed on from elders to youth in daily life events, such as fishing, weaving, communal ventures and meetings of the extended family. The whole community was engaged in the act of making knowledge and defining goals. These were not taught in a formal school curriculum nor were the principles for correct action incorporated in formal legislation. Other, more recent, questions (and fears), such as the possible downstream benefits and the constraints to documenting and sharing these types of knowledge, were also discussed by the participants at the Regional Pacific Ethics of Knowledge Production Workshop.

Documenting the features of indigenous knowledge systems was not seen to be an easy task, given that each nation has its own culture and languages and their histories of contact with non-Pacific peoples are varied. The influence of Christianity received attention, and contributors analysed how, in some cases, Christian belief systems appeared to merge seamlessly with the customary ways, but in other times and places were diametrically opposed to indigenous practices. While acknowledging commonalities of experience and the benefits of joint enterprises, the participants emphasised that ethics programmes must be community-driven and nation-driven and owned, and allowed to evolve in the Pacific way, as in the past. Further, a strong case was made that academic research could provide a framework for communitybased discussion, as would the experiences of Māori in Aotearoa New Zealand, and the innovation of groups such as the Vanuatu Cultural Centre which, in collaboration with community members, has devised and implemented a national research policy aimed at ensuring that ethical protocols are followed in the conduct of research, both by ni-Vanuatu and other external agencies.

Delegates at the Regional Pacific Ethics of Knowledge Production Workshop recognised that a negotiated Pacific ethics framework and mechanism for its implementation (at regional, national and community levels) is vital, given the compelling evidence that the absence of such a mechanism has made the Pacific vulnerable to unethical research practices, including acts of biopiracy. At the same time, such a framework must be Pacific in philosophy and locally grounded in context and take account of the Pacific experience, including the diversity of social, economic and physical, spiritual and cultural contexts in Pacific Small Island Developing States (SIDS). As Peggy FairbairnDunlop (2006) has stated: "The Pacific challenge is to develop a post colonial ethics discourse which is Pacific in philosophy and locally grounded in context". A Pacific set of ethical principles and standards was seen to be invaluable in the context of rapidly developing biotechnologies. The identification of ethical standards would serve as a reminder to Pacific people of their own guiding principles. It would also foster debate on the ethics of science and technology, contribute to new learning among communities and pathways to informed choice, encourage the review and documentation of Pacific ethics, paradigms and processes, contribute to the global research community and protect Pacific SIDS against unethical practices by external as well as national agencies.

\section{The middle ground, a negotiated space and syncretic relationships}

In the articles that follow the authors argue that indigenous, people-based systems of knowledge 
have a valid place in the global pool of human knowledge. Often resisting the binary thinking that opposes tradition and modernity, religion and science and indigenous and western thinking and practices, these articles explore what they describe as the middle ground, a negotiated space or a syncretic relationship between indigenous thinking and western science. In the process they articulate the challenges that Pacific people encounter in their relationship with positivist science and the challenges that Pacific ethical principles and practices pose for those outside the Pacific.

Tui Atua Tupua Tamasese Ta'isi Efi outlines the importance of the Samoan concepts of tapu (the sacred) and tofa sa'ili (the search for wisdom) in identifying what might constitute ethical practices with respect to bioethical research and, more generally, ethical research practice in this context. Drawing on the work of Hans Kung (2007) he argues that it is possible to find a middle ground between ideas and practices grounded in religion, the spiritual, the sacred and science. Against the background of an exploration of different facets of the Samoan concept of tapu, which encompasses the sacredness of the origins of all things as well as the affinity between people, the cosmos, and animate and inanimate earthly phenomena, Tui Atua Tupua Tamasese Ta'isi Efi envisages a Pacific bioethics that involves God-chasing or reaching out for wisdom. This search for knowledge would be grounded in a sense of connectedness to all things, the awareness of people's responsibilities as protectors of the earth, attention to the sacred essence of all things and a desire for increased understanding without ever presuming to know God.

According to Tui Atua Tupua Tamasese Ta'isi Efi, the ethics underpinning this pursuit of knowledge would involve collective decisionmaking because Samoan thinking is always relational. It involves recognition of human vulnerability, humility and a strong sense of the "equation and affinity between all things, animate and inanimate, living and dead". He suggests that knowledge about the beginning of all things is inaccessible via either religion or science but both share a commitment to the passionate pursuit of truth and meaning. A Samoan approach to both requires attention to tapu or the sacred aspects of relatedness.
The challenges of negotiating the relationship between indigenous and western knowledge systems are also explored by Maui Hudson in his consideration of issues for Māori relating to the exercise of collective rights in the ethical review of research. He argues that collective consent does not entail the end of individual consent processes but is a way of assessing the implications of research for a community. Like many Pacific researchers, Hudson is critical of international ethical codes that neglect local social constructs, in particular, the need for community input into the assessment of the ethical features of research projects. His interest is in ethicality - "the situated, specific and experimental ethics talk of citizens". This ethicality, or practice of ethical principles, is not fixed by tradition in indigenous communities, but is context-specific and time-specific, changing in response to new issues and controversies, while also sustained by key concepts, such as the concept of tapu. He argues that determining ethical research practice may involve the development of a negotiated space - a space for deliberation about what will count as knowledge that is informed by several knowledge systems, including science and indigenous knowledge. While recognising that different cultures (including those of the Pacific) often share ethical principles, he argues for attention to the specifics of the local application of those principles and in this respect resists the universalism of the UNESCO UDBHR.

Karlo Mila-Schaaf extends discussion of the concept of negotiated space by focusing attention on the development of the "Guidelines on Pacific health research" by the Health Research Council of New Zealand (2005). At the core of Mila-Schaaf's article is the Pacific concept of $v a$ or the space between people - "the space that connects rather than separates". It is only by nurturing $v a$ that relationships among people and between them and everything else can be sustained. Mila-Schaaf explores the way the Pacific expert group that developed the Guidelines worked to develop a distinctively Pacific viewpoint, while also resisting and adopting some aspects of western, humanistic strands of thinking. She argues that in these respects they were engaged in a post-colonial project that occupied the negotiated space between different knowledge systems. 
The challenges for indigenous people of identifying when collective processes of consent and ethical review are relevant, and when people might engage with science and technology as individuals, is the focus of Mere Roberts' article. She looks at how Māori have had to negotiate systems of community consultation with respect to the regulation of genetically modified organisms and argues for the need to consider both collective and individual rights in making decisions about using novel health technologies. She argues that tensions between indigenous knowledge systems and western science have intensified with the development of new biotechnologies, especially genetic modification. There is a need for regulatory agencies, scientists and scientific institutions to appreciate the complexities surrounding indigenous people's engagement with these technologies, including issues relating to who can speak for Māori and in what context, and when it is appropriate for consultation and consent to be collective and when opportunities to exercise individual rights are important.

Steven Ratuva reminds us that knowledge systems are constantly changing, evolving and responding to other forms of knowledge and different contexts. Colonisation and economic globalisation have facilitated access to diverse knowledge systems and the challenges of operating with multiple ontologies. He suggests that, rather than being opposed and distinct, Pacific traditional knowledge systems and western positivistic science have been involved in a constant process of contradiction and accommodation. This relationship is problematic when western science combines Pacific traditional knowledge and developments in genetic science to assert patents over the flora and fauna that Pacific people see as being subject to their guardianship and control. The assertion of commercial rights by companies is in tension with Pacific people's understanding of knowledge about treasured natural resources as collective resources that have spiritual aspects as well as practical value in the treatment of certain conditions.

This article returns in a very substantive way to the issues raised in the first article by Tamasese Ta'isi Efi, exploring Samoan understandings of tapu, and to Mila-Schaaf's discussion of $v a$ as a spatial and relational concept.
Ratuva argues that the issues posed by patenting are not just commercial issues relating to ownership of certain resources or knowledge about how they can be used with what effects. They relate not only to the bio-chemical effects of kava (a traditional Pacific drink that induces a sense of well-being), but its place as a tapu item in ritual occasions. Ratuva explores the ways in which Pacific states are developing strategies to protect indigenous knowledge, including the Pacific Model Law for the Protection of Traditional Ecological Knowledge, Innovations and Practices. He also outlines the way in which civil society institutions are picking up on these issues and engaging in forms of cultural mapping, aimed at documenting traditional indigenous knowledge, protecting it and preventing its accommodation into western science.

\section{Conclusion}

While each of these articles is intensely appreciative of the local and the specific, they explore issues that are of regional and international significance. How can knowledge arising out of different epistemologies be appropriately incorporated into western science? How are traditional types of knowledge and customary rights over certain flora and fauna to be recognised in national and global systems of knowledge production, commodification and exchange? Who should decide whether certain forms of scientific activity should be undertaken and under what conditions? How can the cultural effects of certain disruptions to genetic continuity be assessed and who should be involved in making decisions about this? What is the relationship between the passions scientists bring to the pursuit of greater knowledge and the Samoan concept of tofa sa'ili, or the pursuit of wisdom? Are there scientists who pursue what Tamasese Ta'isi Efi refers to in his article as faautago loloto or the deep view of the here and now, while other scientists seek tofa mamao, or the long view? And what are the advantages and the dangers of attention to collective decisionmaking by indigenous people on matters relating to approvals for field trials that involve the use of genetic modification as well as the analysis and storage of human genetic information? 
The articles compiled for this Pacific contribution to reflection on global knowledge traverse different positions, assign different weight to the sacred and the secular and provide different responses to the challenges posed by reconciling collective ownership and decisionmaking with attention to individual rights in western political, economic and ethical systems. They draw on the life experience of authors who are at home in the worlds of western culture, natural and social science and the traditional knowledge systems of Samoan, Tongan, Fijian and Māori cultures. These articles are produced by those who, in their daily lives and everyday practice, negotiate the spaces in which indigenous Pacific ethical principles and practices can be articulated, debated, modified and communicated. Our goal, as the editors of this set of articles, is to help these ideas to circulate not only in Pacific contexts, but more broadly as contributions to global knowledge about the ethics of knowledge production.

\section{Notes}

1. The term Pacific is used to refer to both the nation-states of the Pacific Ocean and the large variety of cultures, languages, histories and physical environments that compose the Pacific.

2. This UNESCO Declaration was passed with acclaim by the UNESCO General Conference in Paris in October 2005. The full text was reproduced and introduced in issue 186 of the $I S S J$. It is also available online.

3. Many Māori see themselves as a Pacific people whose ancestors journeyed across the Pacific to Aotearoa and see strong connections between their ontologies and epistemologies and those of people who inhabit the islands of the Pacific. For this reason, those organising the Regional Pacific Ethics of Knowledge Production Workshop decided to include a panel presentation by a group of Māori researchers. Two of these panel members are contributors to this collection of articles.

\section{References}

FAirbairn-Dunlop, P. 2006. Address to the UNESCO Ethics of Knowledge Production Conference, Otago University 12-14 February, 2006. Cited in Ethics of Knowledge Production Conference Report, New Zealand National Commission for UNESCO, Wellington. Available online at http://portal.unesco.org/ shs/en/files/9932/11571219621

Conference_Report.pdf/

Conference_Report.pdf [Accessed 2 November 2009].

Health Research Council of New ZEALAND 2005. "Guidelines on
Pacific health research", Auckland: Health Research Council, available online at http://www.hrc.govt.nz/ assets/pdfs/publications/Pacific $\%$ 20Fact $\%$ 20Sheet.small.pdf [Accessed 27 October 2009].

Kung, H. 2007. The beginning of all things: science and religion. [Transl. by J. Bowden]. Grand Rapids, MI: Wm. B. Eerdmans.

Mila-schaAf, K. 2008. Report of the Regional Pacific Ethics of Knowledge Production Workshop, Apia, 12-14 November. Wellington: National
Commission for UNESCO/Te

Komihana Matua o Aotearoa mô UNESCO. Available online at www.unescobkk.org/fileadmin/ user_upload/shs/EventInfo/UNE SCOAApia2007EthicsofKnowledge. pdf [Accessed 12 November 2009]

UNESCO 2005. Universal declaration on bioethics and human rights. UNESCO, Paris. 